\title{
CAMPESINADO: SU RESISTENCIA A DESAPARECER
}

\section{PEASANT: RESISTANCE TO DISAPPEAR}

\author{
María Fernanda Arguedas Abarca \\ Editora
}

En el número 172 titulado "CAMPESINADO: SU RESISTENCIA A DESAPARECER", Dreby y Rodríguez presentan un estudio sobre la situación de los grupos familiares dedicados a la agricultura en la provincia de Alajuela (cantones de Atenas, Palmares, San Ramón, Grecia y Zarcero) y en la provincia de Cartago en el cantón de Turrialba. Analiza la capacidad de adaptación de estos grupos a las nuevas tecnologías, nuevos valores agregados en los productos y nuevos procesos que han tenido que implementar para enfrentar los retadores cambios que ha conllevado la globalización $y$ los Tratados de Libre Comercio. Sin embargo, los grupos campesinos familiares se han debilitado y sus miembros han procedido ha realizar otro tipo de labores a tiempo parcial para poder sobrevivir. La decisión de muchos jóvenes de estudiar otras carreras para salir de este tipo de negocio familiar que se es un trabajo duro no rentable ha disminuido la continuidad de la producción agrícola. Otro de los nuevos cambios que se han dado es la vinculación de las labores agrícolas con el turismo, al enfocarse en vender un servicio a visitantes, darles la experiencia de una visita $y$ venta de productos, por lo tanto, han surgido estrategias ligadas al agroturismo, comercialización, marketing y educación al consumidor. Esta situación evidencia la falta de políticas agrarias que apoyen a este sector de la población, con mayores apoyos presupuestarios y capacitaciones que les permite vincularse de forma creativa e innovadora a estos nuevos mercados.

Desde México, Villalvazo, Figueroa, Cruz, Sánchez y Olguín realizan un aporte desde el diseño de estrategias a partir de los talleres de agricultura campesina realizados en el Centro Universitario de la Costa Sur (Cucsur) de la Universidad de Guadalajara, México. A partir de la sistematización de experiencias entre campesinos y académicos se desarrollaron nuevas estrategias y métodos de comunicación y educación popular que tomaron en cuenta nociones como "Buen vivir", el "Desarrollo Endógeno" y "El Diálogo de Saberes". Es importante crear y motivar este tipo de espacios que permiten la participación de la población campesina para brindar metodologías alternativas de enseñanza y una educación que transforme estos espacios socio productivos a partir de la experiencia, creencias, saberes, tradiciones, técnicas y realidades. Es un ejemplo de vincular el mundo académico con el mundo de la agricultura campesina desde la investigación-acción, con el fin de trascender los libros y brindar soluciones reales a los diversos grupos sociales.

Otra de las temáticas importantes se centra en el manejo de los recursos hídricos en comunidades rurales. En este sentido, Soares y Camacho analizan la implementación del Programa gubernamental 
ProAgua en comunidades rurales de Puebla en México. Para ello se basan en los conceptos de acceso a la información, transparencia y rendición de cuentas a partir de las percepciones de las personas de las comunidades. Estos conceptos se han implementado desde la vigilancia pública para disminuir los riesgos de corrupción, obtener una mayor confianza hacia el gobierno y obtener una buena gobernanza. Con este trabajo se evidencia grandes divergencias entre la parte formal de comités para la rendición de cuentas y transparencia, y las realidades locales, en donde se presentan debilidades en su conformación y en la capacitación de los comités. Además, la implementación de un buen control de la gestión púbica en donde los programas del Gobierno cumplan con sus objetivos y sus gestores brinden información confiable, oportuna y de calidad, la cual es relevante para la toma de decisiones y realizar los cambios oportunos. Asimismo, brindar mayor información y comunicación a las comunidades para que puedan involucrarse en los comités y se dé una participación más activa de las comunidades en la gestión pública.

Rotman, Miano y Heras analizan los procesos de subjetivación política de los habitantes rurales de las Provincias de Buenos Aires y Chaco, Argentina. Esta decisión de arraigo hacia estos contextos rurales marcados por la vulnerabilidad, la marginación y la violencia. Esta decisión va ligado a la historia y a la dinámica colectiva de las luchas de las familias rurales por sus tierras. Asimismo, la vinculación que se da con la naturaleza y su tierra como sustento de vida, brinda esa visión de permanencia y propiedad. Un punto relevante es la percepción de las familias participantes, las cuales perciben el abandono del Estado y el olvido dentro de las políticas públicas, haciendo que se sientan desprotegidos y busquen otros medios de unión y coalición dentro de las comunidades.

Otro de los puntos de analizar en estos grupos sociales son los mercados rurales o mejor conocidos como tianguis. Teófilo-Salvador hace una investigación etnográfica de la evolución del Tianguis y Plaza Ganadera Ejidal Puente San Bernabé en Almoloya de Juárez, México, en la cual se estudió los diversos actores involucrados en la compra-venta, los giros comerciales, la importancia de las áreas de venta, la presencia peatonal en el mercado, la temporalidad, los cambios de productos $y$ las estaciones del año con mayor afluencia. A pesar de los procesos de marginalidad y abandono de estas regiones, este tianguis ha logrado evolucionar y crecer tomando en consideración las necesidades de sus compradores, compitiendo con grandes mercados $y$ otras formas de negocios. Lo anterior debido a los giros comerciales, la diversidad de productos y servicios, al mismo tiempo que representa un símbolo de tradición en la zona.

Salazar y Cogco hacen un estudio sobre los significados de la educación en las zonas rurales, en este caso, en el ejido El Tigre en el Estado de Tamaulipas, México. Se presenta una reflexión sobre las desigualdades en los planes de educación al considerar una visión homogénea y centralista, sin incluir las visiones y los saberes rurales en la materia educativa, sin reconocer estas realidades diferentes. Un distanciamiento entre los programas curriculares y el contexto rural, al estar enfocado en otras técnicas, lenguajes, vivencias, etc. Por otro lado, se generan un conjunto 
de significados locales entorno a la escuela como proceso socializador, al reconocerse en la vida comunitaria. Se debe incentivar políticas sociales que incluyan a las diversas comunidades a través del diálogo y la experiencia, al comprender diferencias en sus experiencias de vida y de recursos.

En la sección de ARTículos, Sequeira presenta una interesante reflexión desde la vinculación de pobreza-pornografía, en este caso, en la exposición de fotografías de mujeres en condición de pobreza, utilizando como ambientación de las imágenes, sus viviendas pobres, mostrando una clase social baja, lo que se conoce actualmente como pobrezafilia. Esta situación presenta un análisis de la problemática del uso de imágenes en las redes sociales sin autorización de las jóvenes, la ambientación de la foto como eje central de burla y la jerarquización de superioridad a partir de la ofensa.

Piedra realiza un recuento bibliográfico de investigaciones en torno al sector maquila textil y los call centers, a partir de las condiciones laborales, el proceso de globalización y la tercerización de la economía. Se afirma que ambos sectores poseen disimiles condiciones de trabajo, como por ejemplo, el control del tiempo por medio de la informática, máxima productividad vrs condiciones físicas y psicológicas de la población trabajadora, etc.

En el tema de inseguridad, Calonge hace un estudio sobre la percepción de inseguridad y el uso de transporte público en México a partir de la Encuesta Nacional sobre Victimización y Percepción de la Seguridad Pública del 2018, con lo cual se evidencia las diferencias por zonas geográfica y estratificación social. El Estado ha impulsado el uso de transporte público como un medio de movilidad sustentable, pero se ve influenciado por los índices de violencia y la percepción de inseguridad, lo que supone un cambio en su uso y en la finalidad de las políticas públicas.

Desde Argentina, se cuenta con el aporte de Berardi en el tema de militancia sindical en la provincia de Jujuy, con el objetivo de determinar los elementos que inciden en el compromiso político de las personas y las experiencias de cada proceso de militancia. Para ello se utilizó el método de historias de vida para comprender las trayectorias, historias y carreras de cada una de las personas participantes. Lo anterior demostró que cada experiencia posee diversas rupturas y continuidades, a partir de sus experiencias previas, su vinculación, su continuidad en los grupos, los factores motivacionales, los contextos sociales y la lucha por parte de las organizaciones gremiales.

Cano y Silva presentan una reflexión sobre los instrumentos utilizados desde el enfoque de la cultura ciudadana en las políticas públicas. Se realiza una diferenciación entre los instrumentos tradicionales (arte, cultura y comunicación) y los comportamentales (nudge, boost $y$ think) con el fin de que sean medios de intervención de la realidad y resolución de problemas públicos.

Finalizando este número, Carballo propone un marco conceptual para comprender la influencia del género, la sexualidad y la masculinidad en las políticas de población en Costa Rica durante la segunda mitad del 
siglo xx. Estos tres conceptos se articulan dentro de relaciones de poder y política, que inciden enla toma de decisiones y en la percepción social. Para ello se deben considerar y entender la relevancia de agentes externos con los internos (Estado-iglesia), las coyunturas históricas, el contexto demográfico, las clases sociales y las percepciones respecto a género.

Abril-junio, 2021

Ciudad Universitaria Rodrigo Facio 